\title{
Low disabled-2 expression promotes tumor progression and determines poor survival and high recurrence of esophageal squamous cell carcinoma
}

\author{
Wen-Lun Wang ${ }^{1,7}$, Wei-Lun Chang ${ }^{1,2}$, Hsiao-Bai Yang ${ }^{3,4}$, Yu-Chi Wang ${ }^{5}$ I-Wei \\ Chang ${ }^{6}$, Ching-Tai Lee ${ }^{7}$, Chi-Yang Chang7, Jaw-Town Lin ${ }^{7}$, Bor-Shyang Sheu ${ }^{1,2}$ \\ ${ }^{1}$ Institute of Clinical Medicine, National Cheng Kung University Medical Center, Tainan, Taiwan \\ ${ }^{2}$ Department of Internal Medicine, National Cheng Kung University Hospital, Tainan, Taiwan \\ ${ }^{3}$ Department of Pathology, National Cheng Kung University Hospital, Tainan, Taiwan \\ ${ }^{4}$ Department of Pathology, Ton-Yen General Hospital, Hsin-Chu, Taiwan \\ ${ }^{5}$ Department of Biological Science \& Technology, E-Da Hospital/I-Shou University, Kaohsiung, Taiwan \\ ${ }^{6}$ Department of Pathology, E-Da Hospital/I-Shou University, Kaohsiung, Taiwan \\ ${ }^{7}$ Department of Internal Medicine, E-Da Hospital/I-Shou University, Kaohsiung, Taiwan \\ Correspondence to: Bor-Shyang Sheu, email: sheubs@mail.ncku.edu.tw
}

Keywords: disabled-2, survival, recurrence, esophageal cancer

Received: September 02, $2015 \quad$ Accepted: February 24, $2016 \quad$ Published: March 29, 2016

\section{ABSTRACT}

Patients with esophageal squamous cell carcinomas (ESCCs) have poor survival and high recurrence rate, but lack a prognostic biomarker. Disabled-2 (DAB2) is a crucial tumor suppressor, but its roles in ESCCs are uncertain. We investigated whether low DAB2 expression in ESCCs could lead into tumor progression and poor prognosis. Our results found patients with low-DAB2 expression ESCCs had significantly larger tumor size, deeper tumor invasion depth, lymph node metastasis, worse survival, and higher recurrence rate $(P<0.05)$. The Cox-regression model revealed low-DAB2 expression was an independent factor of poor survival $(P<0.05)$, and also of tumor recurrence with the predictive performance superior to clinical TNM stage $(P<0.05)$. Low-DAB2 cancer cells, validated by DAB2 knockdown or overexpression, had higher phosphorylated ERK and migration abilities, which could be suppressed by ERK inhibitor treatment. TGF- $\beta$-induced epithelial-to-mesenchymal transition (EMT) only existed in the high-DAB2 cells, and related to worse prognosis of high-DAB2 ESCCs $(P<0.05)$. In conclusion, DAB2 can suppress the ERK signaling, but correlate to have TGF- $\beta$-induced EMT in ESCCs. DAB2 expression could be a biomarker to identify patients with worse survival and high recurrence. Our data suggest DAB2 expression can stratify patients in need of aggressive surveillance and with possible benefit from anti-ERK or anti-TGF- $\beta$ therapies.

\section{INTRODUCTION}

Esophageal cancer is a highly lethal disease, causing more than 400,000 deaths per year in the world [1]. In the Asia-Pacific region, esophageal squamous cell carcinoma (ESCC) is the major disease phenotype with an increased incidence in recent years [1,2]. Despite recent advances in multi-disciplinary treatment, including radical surgical resection, chemotherapy, and radiotherapy, the 5-year survival rates of patients with ESCC remains less than 30\% [2-7]. The high recurrence rate (around
40 to $60 \%$ ) after curative surgery or definitive chemoradiation therapy is the leading cause of death for such patients [8-12]. However, we continue to lack prognostic biomarkers to identify the risky patients with tumor recurrence and poor survival.

Disabled-2 (DAB2) is a multifunctional adapter protein with tumor suppressor activity, which may act as a potent negative regulator of multiple signaling pathways, including the ERK [13-15], Wnt/ $\beta$-catenin [16-18], and TGF- $\beta[19,20]$ pathways. DAB2 is also shown to participate in TGF- $\beta$ induced epithelial-to-mesenchymal 
transition (EMT) [21-24]. A decreased DAB2 expression has been shown in many types of tumors, including head \& neck [20], lung [25], ovarian [26], prostate [27], breast [28], and also esophageal cancers [29]. A recent study revealed the DAB2 expression level can predict metastasis and poor prognosis in human squamous cell carcinomas of the head \& neck [20]. Nevertheless, the clinical implication of DAB2 in the ESCC, in eager need of a prognosis biomarker, remains uncertain. This study is thus highly original to illustrate low DAB2 expression level can be a prognostic biomarker for the recurrence and survival of patients with ESCC. Moreover, the study disclosed DAB2 can suppress the ERK signaling, but may correlate to have TGF- $\beta$-induced epithelial-to-mesenchymal transition (EMT) in ESCC. The study suggests DAB2 expression may not only stratify patients who require aggressive surveillance, but also point out the cases with potential benefit from anti-ERK or antiTGF- $\beta$ therapies for ESCC.

(A)

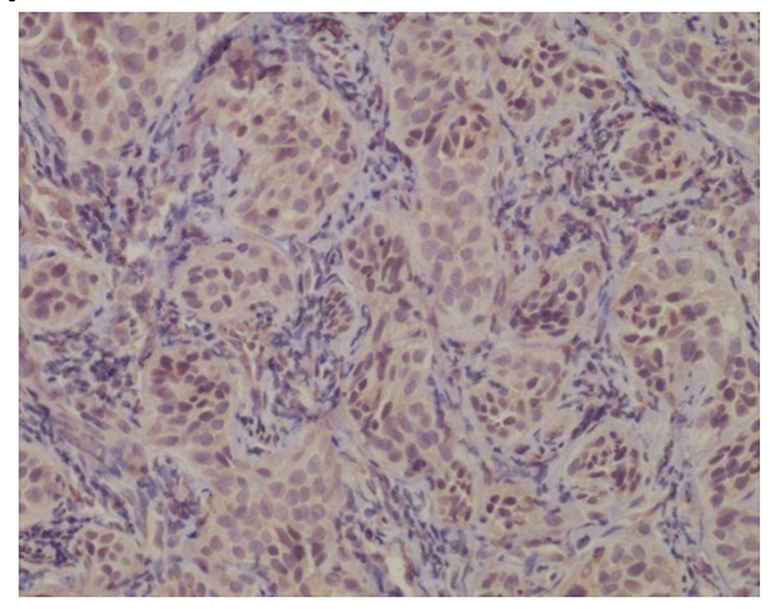

(C)

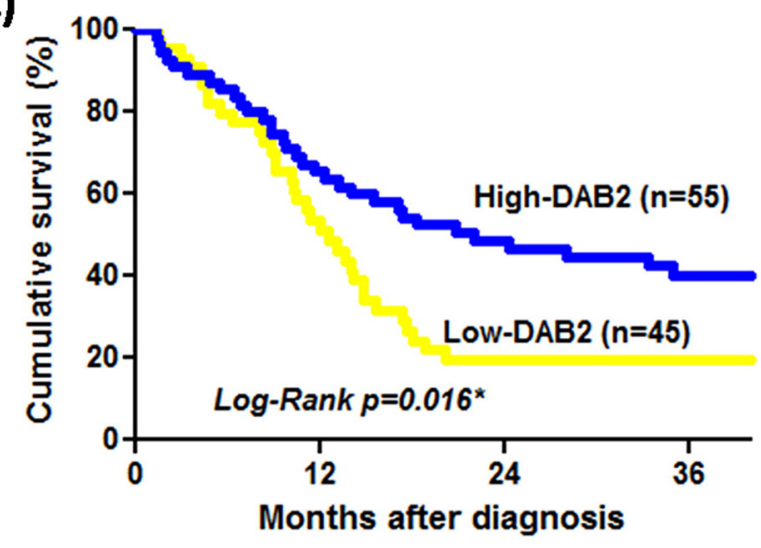

\section{RESULTS}

\section{Demographic features of the ESCC patients with high- and low-DAB2 expressions}

Forty-five of 100 patients with ESCC defined to have low-DAB2 expression carcinomas (Figure 1A \& 1B). In Table 1, as compared to the ESCC with high-DAB2 expression, the ESCC with low-DAB2 expression can be a larger tumor size, more tumor invasion depth, higher frequency of lymph node metastasis, and more advanced clinical stage $(P<0.05)$.

\section{DAB2 expression and the survival of patients with ESCC}

Among these 100 patients, 46 were treated with operation, 26 with definitive chemoradiation therapy and 28 with palliative chemotherapy. The Coxregression model confirmed the age, tumor size and

(B)

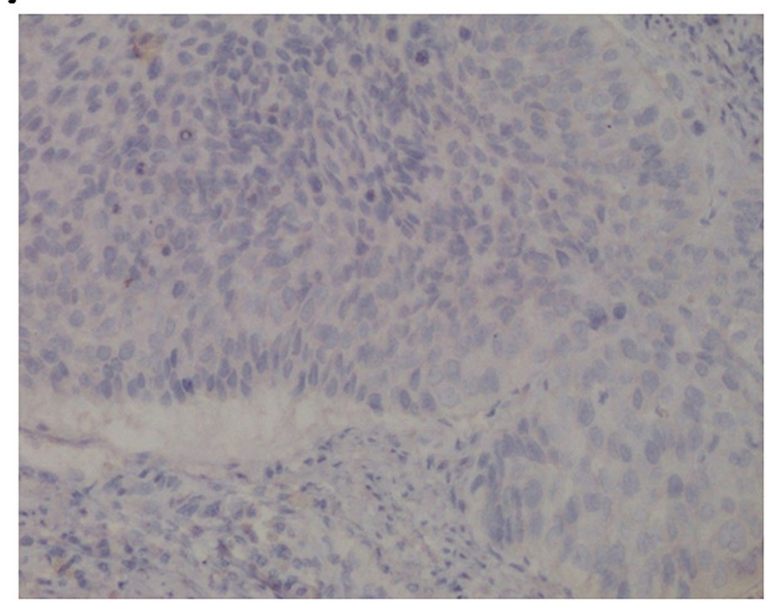

(D)

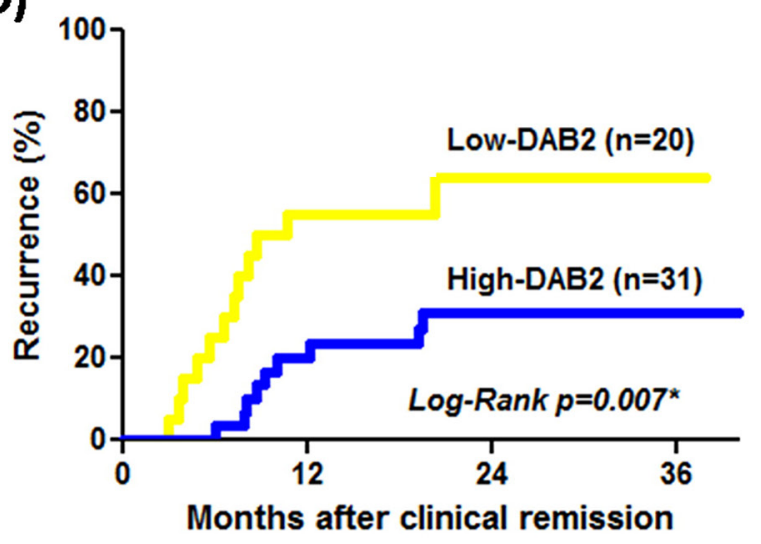

Figure 1: The DAB2 protein of ESCC can be correlated to survival and tumor recurrence rate. A. High-DAB2 ESCC with cytoplasmic brownish staining of DAB2 protein; B. Low-DAB2 ESCC with loss of DAB2 protein (original magnification x 200); C. The survival rate by Kaplan-Meier survival curve was lower in patients with low-DAB2 ESCC than in those with high-DAB2 ESCC $(P=0.016)$. D. The tumor recurrence rate was higher in patients with low-DAB2 ESCC than in those with high-DAB2 ESCC $(P=0.007)$. 
Table 1: The correlation of DAB2 expression level to the clinical features of ESCCs

\begin{tabular}{|c|c|c|c|c|}
\hline \multirow[t]{2}{*}{ Characteristics n (\%) } & \multirow[b]{2}{*}{ (n) } & \multirow{2}{*}{$\frac{\text { High DAB2 }}{(n=55)}$} & \multirow{2}{*}{$\frac{\text { Low DAB2 }}{(n=45)}$} & \multirow{2}{*}{$\begin{array}{c}p \\
\text { value }\end{array}$} \\
\hline & & & & \\
\hline \multicolumn{5}{|l|}{ Age, years } \\
\hline$\leq 50$ & 47 & $28(60 \%)$ & $19(40 \%)$ & 0.425 \\
\hline$>50$ & 53 & $27(51 \%)$ & $26(49 \%)$ & \\
\hline \multicolumn{5}{|l|}{ Tumor differentiation } \\
\hline well or moderate & 92 & $49(48 \%)$ & $43(52 \%)$ & 0.289 \\
\hline poor & 8 & $6(75 \%)$ & $2(25 \%)$ & \\
\hline \multicolumn{5}{|l|}{ Primary tumor size } \\
\hline$\leq 4 \mathrm{~cm}$ & 39 & $28(72 \%)$ & $11(28 \%)$ & 0.008 \\
\hline$>4 \mathrm{~cm}$ & 61 & $27(44 \%)$ & $34(56 \%)$ & \\
\hline \multicolumn{5}{|l|}{ Clinical stage } \\
\hline I or II & 23 & $18(78 \%)$ & $5(22 \%)$ & 0.016 \\
\hline III or IV & 77 & $37(48 \%)$ & $40(52 \%)$ & \\
\hline \multicolumn{5}{|l|}{ Invasion depth } \\
\hline $\mathrm{T} 1-2$ & 24 & $19(79 \%)$ & $5(21 \%)$ & 0.009 \\
\hline T3-4 & 76 & $36(47 \%)$ & $40(53 \%)$ & \\
\hline \multicolumn{5}{|l|}{ Lymph node } \\
\hline negative & 15 & $12(80 \%)$ & $3(20 \%)$ & 0.048 \\
\hline positive & 85 & $43(51 \%)$ & $42(49 \%)$ & \\
\hline \multicolumn{5}{|l|}{ Distant metastasis } \\
\hline negative & 72 & $43(60 \%)$ & $29(40 \%)$ & 0.179 \\
\hline positive & 28 & $12(43 \%)$ & $16(57 \%)$ & \\
\hline
\end{tabular}

ESCC: esophageal squamous cell carcinoma.

tumor differentiation were not related with poor survival of ESCC. Both low-DAB2 levels in tumors ( $\mathrm{HR}=1.81$, $P=0.017)$ and clinical advanced stage $(\mathrm{HR}=3.49, P=0.001)$ were independent factors of poor ESCC survival (Table 2). In Figure 1C, patients with low-DAB2 ESCC have worse survival than those with high-DAB2 ESCC ( $P=0.016$, by log-rank test).

\section{DAB2 expression levels and ESCC recurrence}

After initial treatment for the 100 ESCC patients, there were 51 patients defined to have achieved clinically complete remission. Among them, 40 received operationbased treatment and 11 definitive chemoradiation therapy with curative intent. There were 20 of $51(41.2 \%)$ patients which developed tumor recurrence at either local or distant sites during the follow-up period. In Table 3, the Coxregression model revealed that low-DAB2 expression in the pretreatment tumor of patients with ESCC achieved clinical complete remission could be an independent factor to identify patients with recurrence of ESCC (HR: 2.57, $P=0.041$ ). The predictive performance of low-DAB2 on ESCC tissue is even more superior to the clinical TNM stage or treatment modalities (Table 3). In Figure 1D, the patients with low-DAB2 ESCC had a higher recurrence rate than those with high-DAB2 ESCC ( $P=0.007$ by LogRank test).

\section{Low disabled-2 expression promotes tumor progression via activation of ERK signaling}

The DAB2 expression levels of five human ESCC cell lines (KYSE-50, KYSE-70, KYSE-150, KYSE-170, KYSE-510) and a human normal esophageal squamous epithelial cell line (Het-1A) were assessed by western blot (Figure 2A). The KYSE-150 and KYSE-510 ESCC cells showed low-DAB2 expression, as compared to normal epithelial cell with high DAB2 expression (Figure 2A). The low-DAB2 expression cell lines (KYSE-150 and KYSE-510) constituted higher migration properties in the 
Table 2: The factors related to poor survival of patients with ESCC by Cox hazard regression

\begin{tabular}{lccccc}
\hline Factors & Variable & Case No. & $\mathbf{9 5 \%}$ CI & HR & $\boldsymbol{p}$ value \\
\hline Age & $>50$ vs. $\geqq 50$ & $53 / 47$ & $0.81-2.14$ & 1.31 & 0.321 \\
Tumor size & $>5 \mathrm{~cm}$ vs. $\geqq 5 \mathrm{~cm}$ & $47 / 53$ & $0.82-2.17$ & 1.34 & 0.619 \\
Differentiation & Poorly vs. moderate & $8 / 92$ & $0.62-3.34$ & 1.44 & 0.360 \\
ESCC stage & III, IV vs. I,II & $77 / 23$ & $1.72-7.09$ & 3.49 & $\mathbf{0 . 0 0 1}$ \\
DAB2 & Low vs. High & $45 / 55$ & $1.11-2.96$ & 1.81 & $\mathbf{0 . 0 1 7}$ \\
\hline
\end{tabular}

Abbreviations: HR, hazard ratio; CI, confidence interval; ESCC: esophageal squamous cell carcinoma.

Table 3: The independent factors to predict tumor recurrence by Cox hazard regression

\begin{tabular}{lccccc}
\hline Factors & Variable & Case No. & $\mathbf{9 5 \%}$ CI & HR & $\boldsymbol{p}$ value \\
\hline Univariate & & & & & \\
Age & $>50$ vs. $\geqq 50$ & $21 / 30$ & $0.50-2.85$ & 1.20 & 0.683 \\
Tumor size & $>4 \mathrm{~cm}$ vs. $\geqq 4 \mathrm{~cm}$ & $29 / 22$ & $0.52-2.88$ & 1.23 & 0.643 \\
Differentiation & Poor vs. moderate & $5 / 46$ & $0.31-5.74$ & 1.33 & 0.700 \\
ESCC stage & III vs. I, II & $30 / 21$ & $0.98-7.33$ & 2.68 & 0.055 \\
Treatment & Definitive CRT vs. & $11 / 40$ & $1.01-5.89$ & $\mathbf{2 . 4 4}$ & $\mathbf{0 . 0 4 7}$ \\
& OP-based* & & & \\
DAB2 & Low vs. High & $20 / 31$ & $1.31-7.46$ & $\mathbf{3 . 1 2}$ & $\mathbf{0 . 0 1 0}$ \\
Multivariate & III vs. I,II & $30 / 21$ & $0.57-4.88$ & 1.66 & 0.357 \\
ESCC stage & OP-based* & $11 / 40$ & $0.80-4.92$ & 1.98 & 0.142 \\
Treatment & Low vs. High & $20 / 31$ & $1.04-6.36$ & $\mathbf{2 . 5 7}$ & $\mathbf{0 . 0 4 1}$ \\
DAB2 & Dinitive CRT vs. & & & \\
\hline
\end{tabular}

Abbreviations: HR, hazard ratio; CI, confidence interval; ESCC: esophageal squamous cell carcinoma; OP-based*, indicated the patient had received esophagectomy; CRT: concurrent chemoradiation.

cell horizontal and vertical migration abilities by wound closure test and transwell migration assay (Figure 2B).

To explore the underlying mechanisms, we investigated whether the higher invasive property of low-DAB2 cancer was attributed to up-regulation of ERK or Wnt/ $\beta$-catenin pathways. We found low-DAB2 cancer cells were associated with higher expressions of phosphorylated ERK 1/2 (p-ERK 1/2) (Figure 2C). The DAB2 expressions in cells were inversely correlated with phosphorylated ERK and the ESCC migration abilities (Figure 2D). Similarly, in clinical tumor tissues (Figure 3A), the low-DAB2 ESCC tended to have higher phosphorylated ERK $(P=0.02)$. However, the DAB2 expression level did not correlate with $\beta$-catenin expression. These findings suggest that low-DAB2 cancers may constitute higher migration abilities via the upregulation of ERK signaling.

We further performed knockdown studies for highDAB2 cell lines (KYSE-50, KYSE-70) by siRNA targeted against DAB2. In Figure 4, the down-regulation of DAB2 by siRNA targeting increased cancer cell motility and ERK phosphrylation. In Figure 5, the over-expression of DAB2 in the low-DAB2 cell line (KYSE-150) suppressed the ERK phosphorylation and cancer cell motility. Treating with Erk inhibitors (Merk Millipore, FR180204; 60 $\mu \mathrm{M}$ ) to the low-DAB2 cell line (KYSE-150) can inhibit the cancer cell migration (Figure 3B-3D).

\section{Low-DAB2 expression level has no EMT}

Because DAB2 participates in the TGF- $\beta$-induced EMT [21-23], this study tested whether DAB2 expression correlated with the EMT phenotype of ESCC. Our study illustrated EMT phenotype only appeared in the high-DAB2 ESCC cell lines, but not in the low-DAB2 ones (Figure 6A). The data suggested the higher cancer migration ability of low-DAB2 cancer cell lines should be EMT-independent manner.

In Figure 6B, the high-DAB2 (KYSE-50) cells treated with TGF- $\beta$ can induce EMT phenotype. In 
contrast, the low-DAB2 (KYSE-150) cells treated with TGF- $\beta$ cannot induce EMT. Similarly, in primary tumor tissues (Figure 6C), EMT phenotypes were more common in high-DAB2 ESCC than in low-DAB2 ones $(25.5 \%$ [14/55] vs. $6.7 \%$ [3/45], $P=0.016)$. Moreover, EMT was significantly correlated with a poor survival for ESCC in high-DAB2 cancers $(p=0.04)$, but not in low-DAB2 cancers (Figure 6D \& 6E).

\section{Methylation status of DAB2 promoter in ESCC}

The study further validate whether aberrant hypermethylation of the promoter in $D A B 2$ gene may correlate to low DAB-2 expression in ESCC. Because there were $53 \mathrm{CpG}$ dinucleotides in the $D A B 2$ promoter region, we further evaluated the possibility of methylationmediated gene silencing of $D A B 2$ promoter in 45 lowDAB2 ESCC patients by the methylation-specific PCR (Figure 7A). However, only 13 out of 45 (29\%) patients with low-DAB2 ESCC had aberrant $D A B 2$ promoter hypermethylation. Moreover, the methylation status of DAB2 promoter was not well correlated to DAB2 expression in ESCC cell lines (Figure 7A). Some high-
DAB2 cell lines (KYSE-50, KYSE-70) even were demonstrated with DAB2 promoter hypermethylation. The data suggests that other mechanisms beyond to $D A B 2$ promoter hypermethylation can regulate DAB2 expression.

\section{DISCUSSION}

This study provides the first integrated investigation of DAB2 in ESCC at both cellular and clinical levels. We illustrated low-DAB2 level cancer cells constitute an invasive property, probably via activation of ERK signaling. A low-DAB2 expression can be an independent biomarker of worse survival and high recurrence for ESCC, even with better predictive performance than clinical TNM stages.

Decrease of DAB2 protein may occur early since the ESCC development, and sustain to drop-down along with tumorigenic pathway [29]. However, there remains without available data to verify the clinical significance of DAB2 down-regulation in ESCC. In Table 1, the low-DAB2 expression of ESCC tissue was
(A)

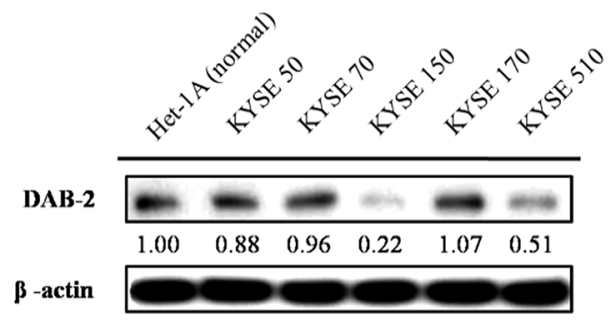

(C)

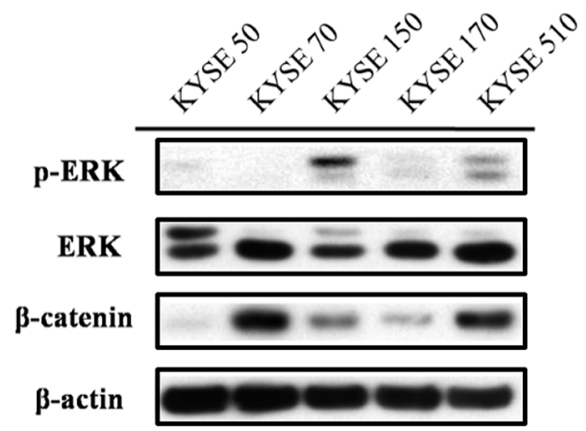

(B)

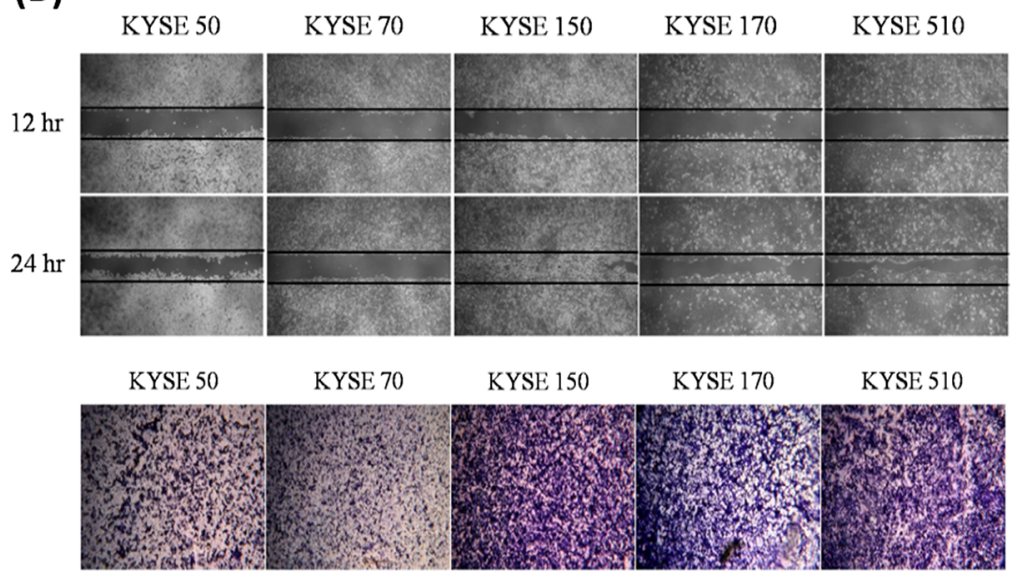

(D)

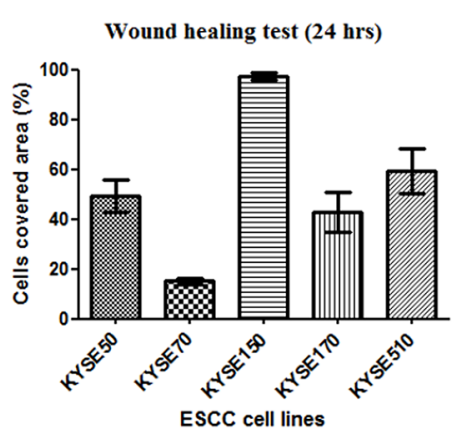

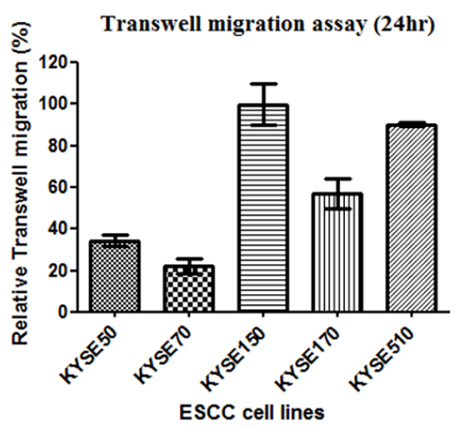

Figure 2: The low-DAB2 esophageal cancer cells had a higher phosphorylated ERK (p-ERK) expression and migration abilities. A. The western blot analysis of DAB2 protein in five ESCC cell lines (KYSE) and human normal esophageal squamous epithelial cell line (Het-1A). B. The wound healing assay (upper panel) and transwell migration assay (lower panel) to evaluate the horizontal and vertical migration abilities in ESCC cell lines. C. TheERK, p-ERK and $\beta$-catenin levels in ESCC cell lines. D. The quantitative representation of migration abilities in ESCC cell lines. 
significantly associated with a larger tumor size, a deeper tumor invasion, and a higher frequency of lymph node metastasis. Furthermore, such a low-DAB2 expression tumor may lead into a worse survival. To the best of our knowledge, this is the first study to explore the clinical significance and provided clinical evidence that DAB2 may participate in the process of ESCC progression and may correlate with survival.

DAB2 is a well-established tumor-suppressor and a cytoplasmic adaptor molecule, has been shown to link

(A)

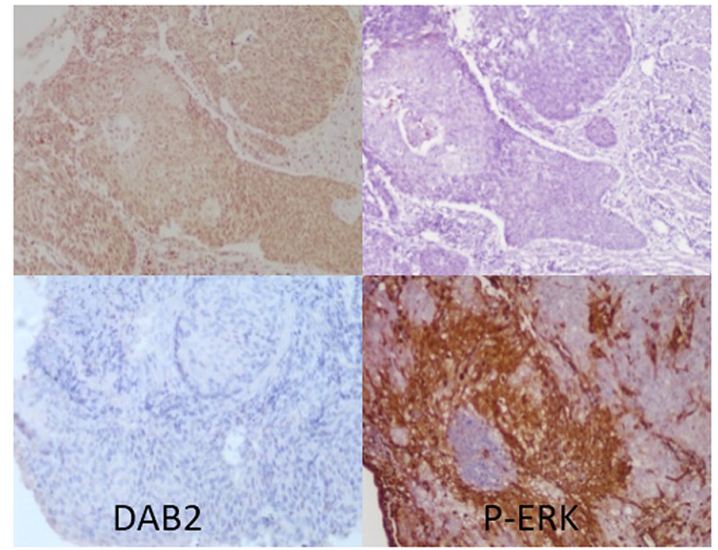

(C)
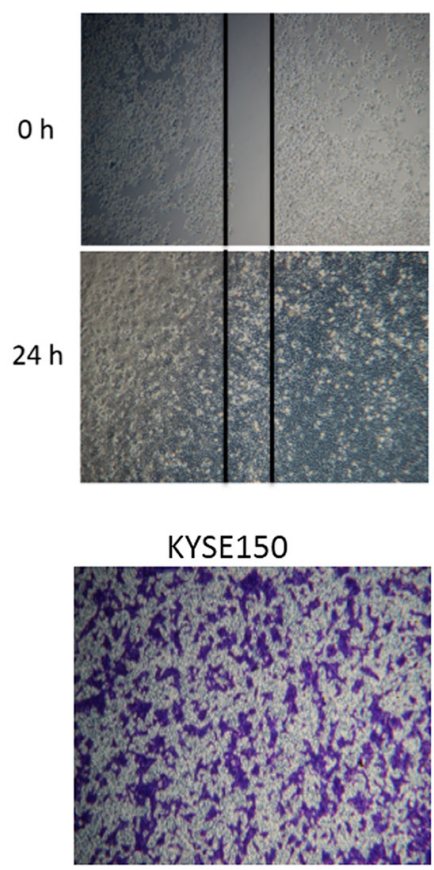

KYSE150 + Erk inhibitor

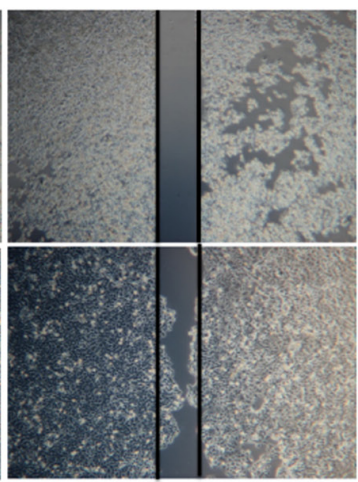

KYSE150+Erk inhibitor

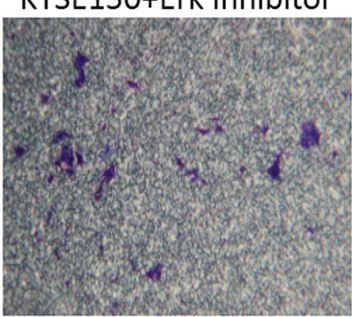

cell surface receptors to downstream signal transduction, especially the ERK [13-15], Wnt/ $\beta$-catenin [16-18] and TGF- $\beta$ signaling pathway $[19,20]$. DAB2 can suppress ERK phosphorylation [13]. Our study also demonstrates DAB2 function as a repressor of ERK signaling in ESCC cell lines, i.e. low-DAB2 cells can associate to higher levels of ERK phosphorylation, and vice versa. Activation of ERK signaling is a frequent event in tumorigenesis, and has been implicated in cell migration, and angiogenesis, events that are essential for metastasis [33, 34]. In
(B)

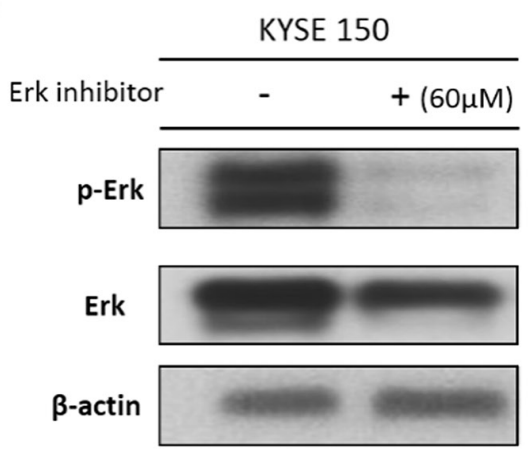

(D)
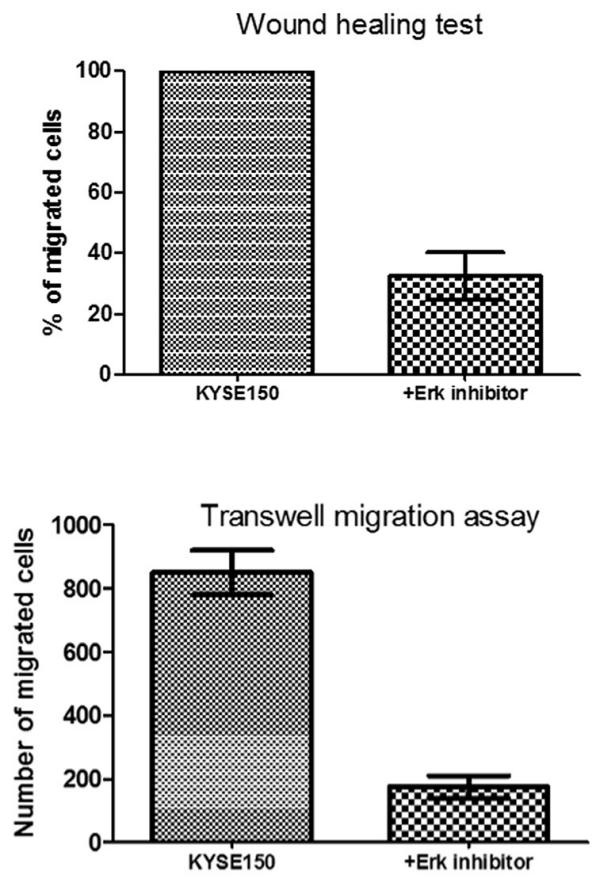

Figure 3: The associations between DAB2 and p-ERK in clinical tumor samples and cell lines. A. The high-DAB2 cancer (upper panel) had lower p-ERK (upper-right panel) expression, evaluated by immunohistochemistry in clinical tumor samples. The lowDAB2 cancer had higher p-ERK level (lower panel). B. The western blot confirmed the suppression of Erk phosphorylation by Erk inhibitor; C. The wound healing test (upper panel) and transwell migration assay (lower panel) showed the treatment with ERK inhibitor suppress cancer cell motility of low-DAB2 cell lines; $\mathbf{D}$. The quantitative representation of migration abilities in low-DAB2 ESCC cell lines before and after ERK inhibitor treatment. 
addition, ERK had been reported to phosphorylate HIF$1 \alpha$, resulting in the induction of VEGF expression, and promoting angiogenesis $[33,35]$. Activation of the ERK pathway can also link to expression of MMP-9 [36], which may degrade the extracellular matrix to lead into a worse prognosis of ESCC as shown in our previous study [37]. Taken together, this evidence supports the reason of why low-DAB2 ESCC may have a poor survival and a high risk of recurrence.

DAB2 may serves as a negative regulator of canonical Wnt/ $\beta$-catenin signaling by stabilizing the $\beta$-catenin degradation complex $[16,17]$. However, our study did not disclose that DAB2 cannot inhibit the $\beta$-catenin accumulation in ESCC cell lines. Our data was highly original to show the EMT phenotype could be only disclosed in high-DAB2 ESCC, but not in lowDAB2 ESCC. This data supported the previous reports to confirm DAB2 shall be involved to TGF- $\beta$ induced EMT [21-24].
As EMT can link to aggressive, invasive and metastatic behavior of various cancer types [38, 39], including ESCC [40, 41], our study further tested whether EMT phenotype alone can be related with the survival of ESCC. Only in the case of high-DAB2 $\mathrm{ESCC}$, but not in low-DAB2 ESCC, the presence of EMT can determine a worse prognosis of ESCC. Accordingly, DAB2 shall carry on a dual-role manner during tumor progression. The first is that DAB2 serves as suppressor of ERK signaling. Alternatively, it may bridge TGF- $\beta$ receptors to induce EMT process in a subset of patients. We thus suggested the patients with ESCC could be divided into three phenotypes (Figure 7B): 1> low-DAB2, 2> high-DAB2 with EMT, and 3> high-DAB2 without EMT; with corresponding 2-year overall survival rate as $20 \%, 30 \%$ and $60 \%$, respectively. Such differentiated phenotypes shall be helpful for clinicians to categorize the risk of ESCC with regards to survival.
(A)

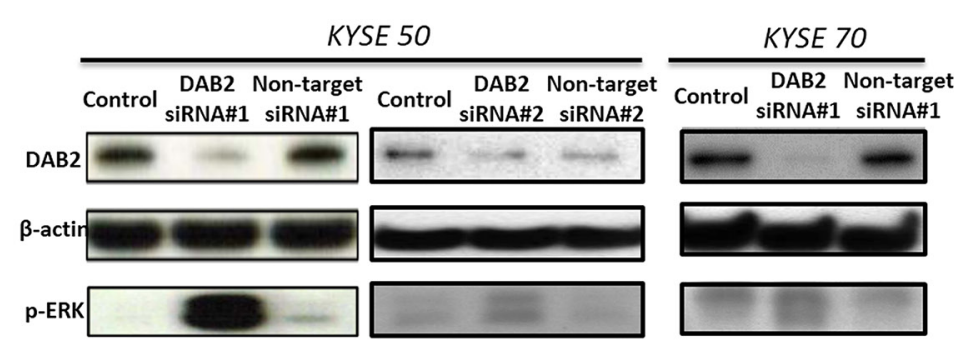

(C)

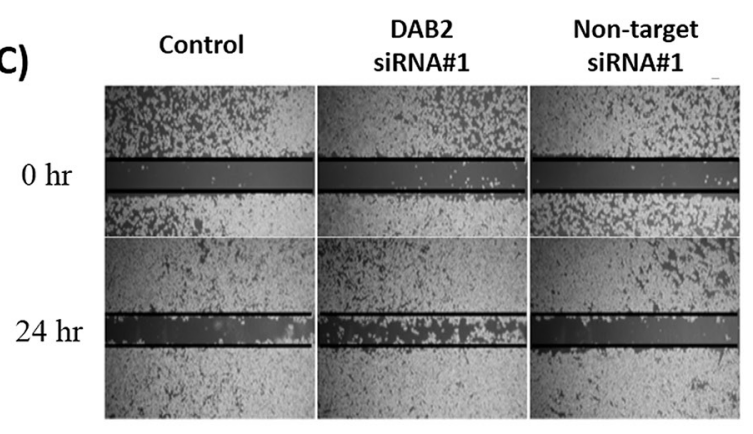

(D)

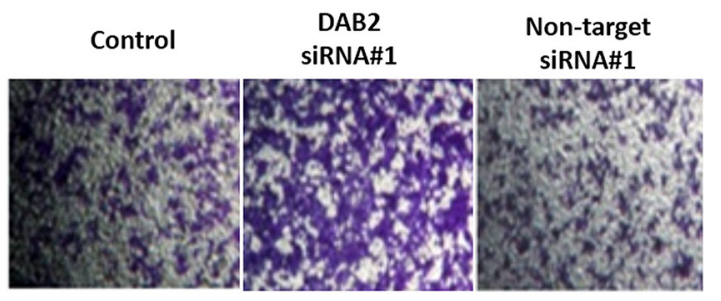

(B)
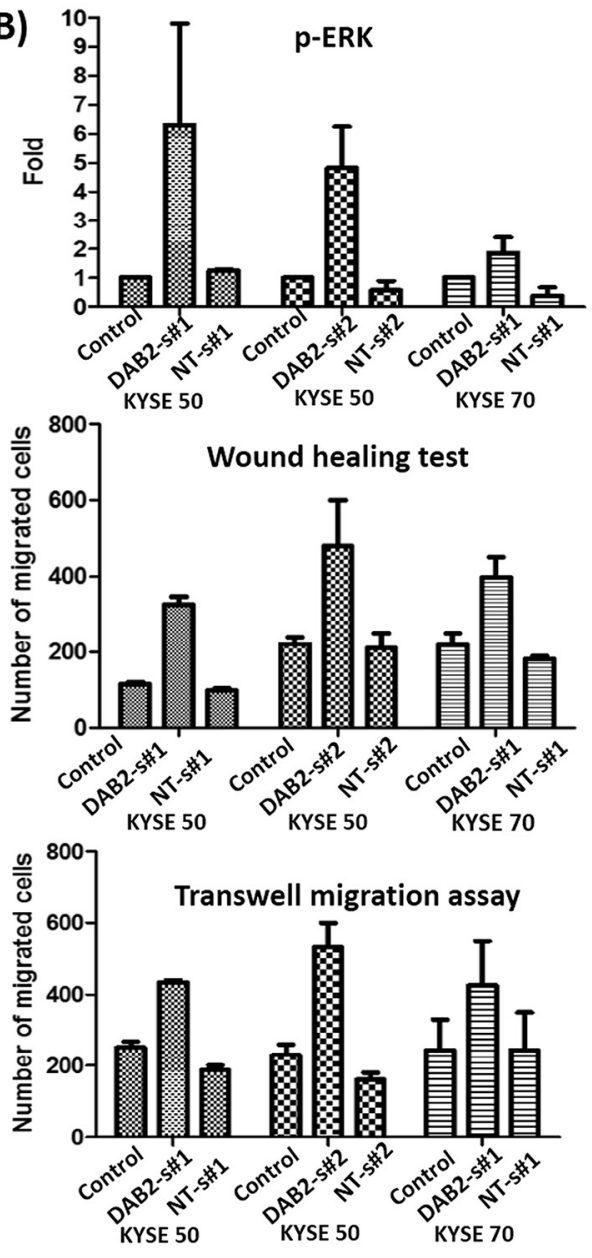

Figure 4: The down-regulation of DAB2 by siRNA in high-DAB2 cell lines promoted ERK phosphorylation and cell motility. A. Western blot confirmed down-regulation of DAB2 by siRNA in KYSE-50 and KYSE-70 cell lines. B. DAB2 down-regulation promoted ERK phosphorylation. The wound healing $\mathbf{C}$. and transwell migration assay $\mathbf{D}$. showed DAB2 down-regulation promoted cancer cell migration (Abbreviation: s\#1: siRNA\#1;s\#2: siRNA\#1; NT, Non-target). 
(A)

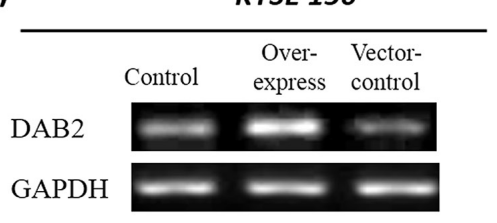

(C)

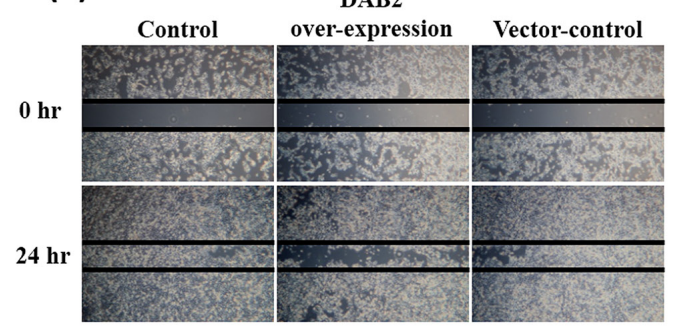

(D)

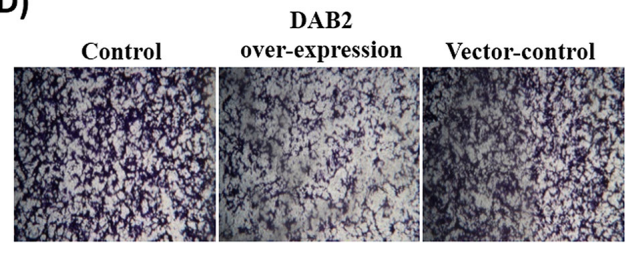

(B)
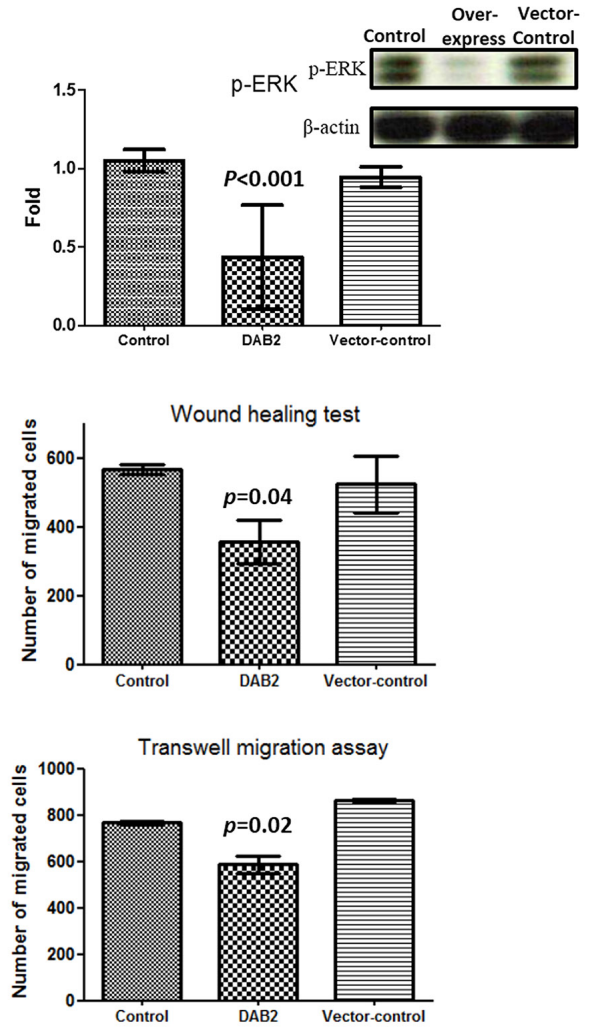

Figure 5: The over-expression of DAB2 can suppress ERK phosphorylation and cancer cell motility. A. Reverse transcription PCR confirmed the over-expression of DAB2 in Low-DAB2 (KYSE-150) cell line. B. DAB2 over-expression inhibited ERK phosphorylation. C, D. The wound healing and transwell migration assay showed DAB2 over-expression suppressed cell migration.

(A)

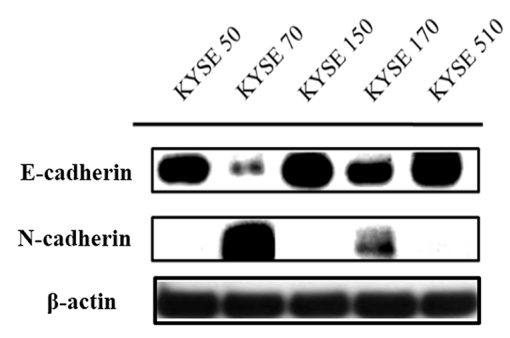

(B)
(C) EMT phenotype:

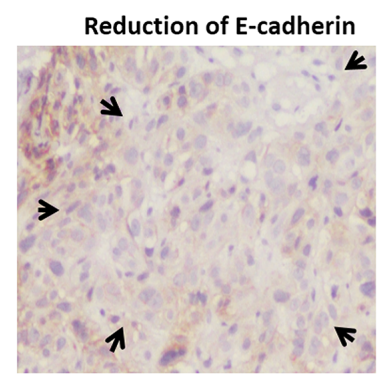

(D) Overall ESCC

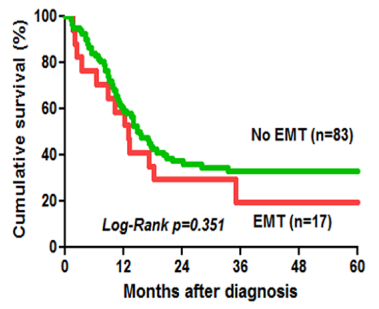

(E) In high-DAB2 ESCC

Positive N-cadherin
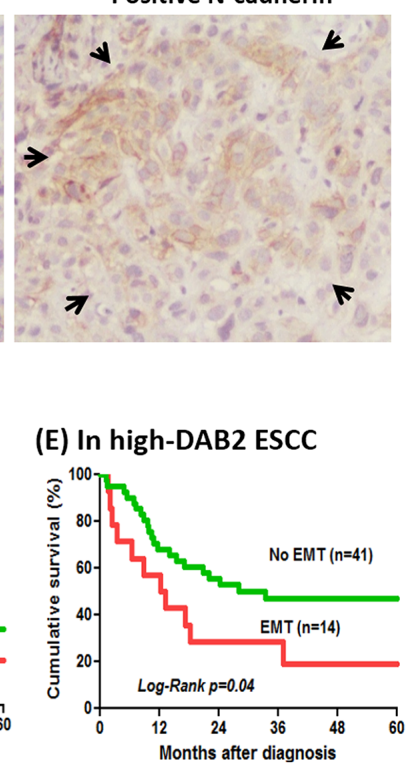

Figure 6: The high-DAB2 esophageal cancer cell had the presence of epithelial-mesenchymal transition (EMT). A. Western blot showed EMT phenotype appeared only in high-DAB2 cell lines, KYSE-70 \& -170 . B. Treatment with TGF- $\beta(5 \mathrm{ng} / \mathrm{ml})$ for high-DAB2 (KYSE-50) and low-DAB2 (KYSE-150) ESCC cells, respectively. TGF- $\beta$ can induce N-cadherin and $\beta$-catenin expression in KYSE-50, but not in KYSE-150. C. EMT phenotype with reduced E-cadherin and increased N-cadherin expression (arrow) in clinical tumor tissues by immunohistochemistry. The survival analysis by Kaplan-Meier survival curves showed EMT had survival impact on the patients with high-DAB2 cancers $(p=0.04)$ D. but not in low-DAB2 cancers $\mathbf{E}$. 
The silencing of $D A B 2$ gene expression can be modified by epigenetic changes [20, 42, 43]. The aberrant $D A B 2$ promoter methylation was detected in 13 of 45 (29\%) patients with low-DAB2 ESCC in our study. This data suggested $D A B 2$ promoter hypermethylation just decreased DAB2 expression in a subset of ESCC. There should be other mechanisms responsible to low DAB2 in ESCC, especially for those with unmethylated $D A B 2$ promoters.

Based on COX hazard regression analysis (Table 3), low-DAB2 expression of ESCC is even superior to clinical tumor staging to predict the recurrence after treatment. Our data illustrated that DAB-2 expression can be a convenient biomarker to select high-risk ESCC patients to receive more intensive treatment before recurrence occurs. In addition, specific blockade of the ERK pathway has been suggested as an attractive pharmacological target to limit malignant progression and metastasis [33, 44, 45]. Our data illustrated the Erk inhibitors suppressed cell migration in the low-DAB2 cancer cell lines. These data supported ESCC with low-DAB2 expression, commonly associated with high ERK signaling, may be good candidates to receive ERK-targeted therapeutics.

In conclusion, the DAB2 expression levels in ESCC can serve as clinical biomarker to identify patients with poor survival and high-risk of recurrence. ESCC with lowDAB2 expression, or those with high-DAB2 and EMT, shall not only has a worse prognosis, but also provide a guidance to select the suitable target therapy in future.

(A) MSP
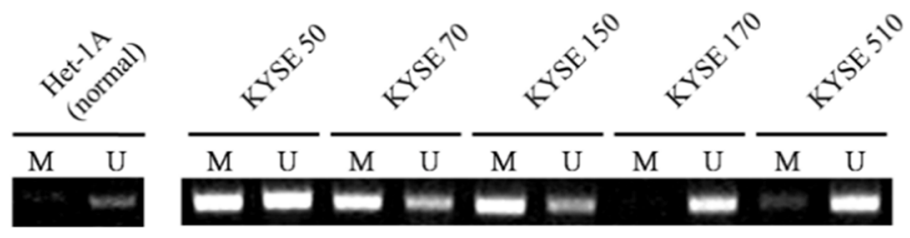

$\frac{1}{U} \quad M \frac{2}{U} \frac{3}{U} \frac{4}{U} \frac{M}{U} \frac{5}{U} \frac{6}{U M}$

\section{(B) Schematic algorithm}
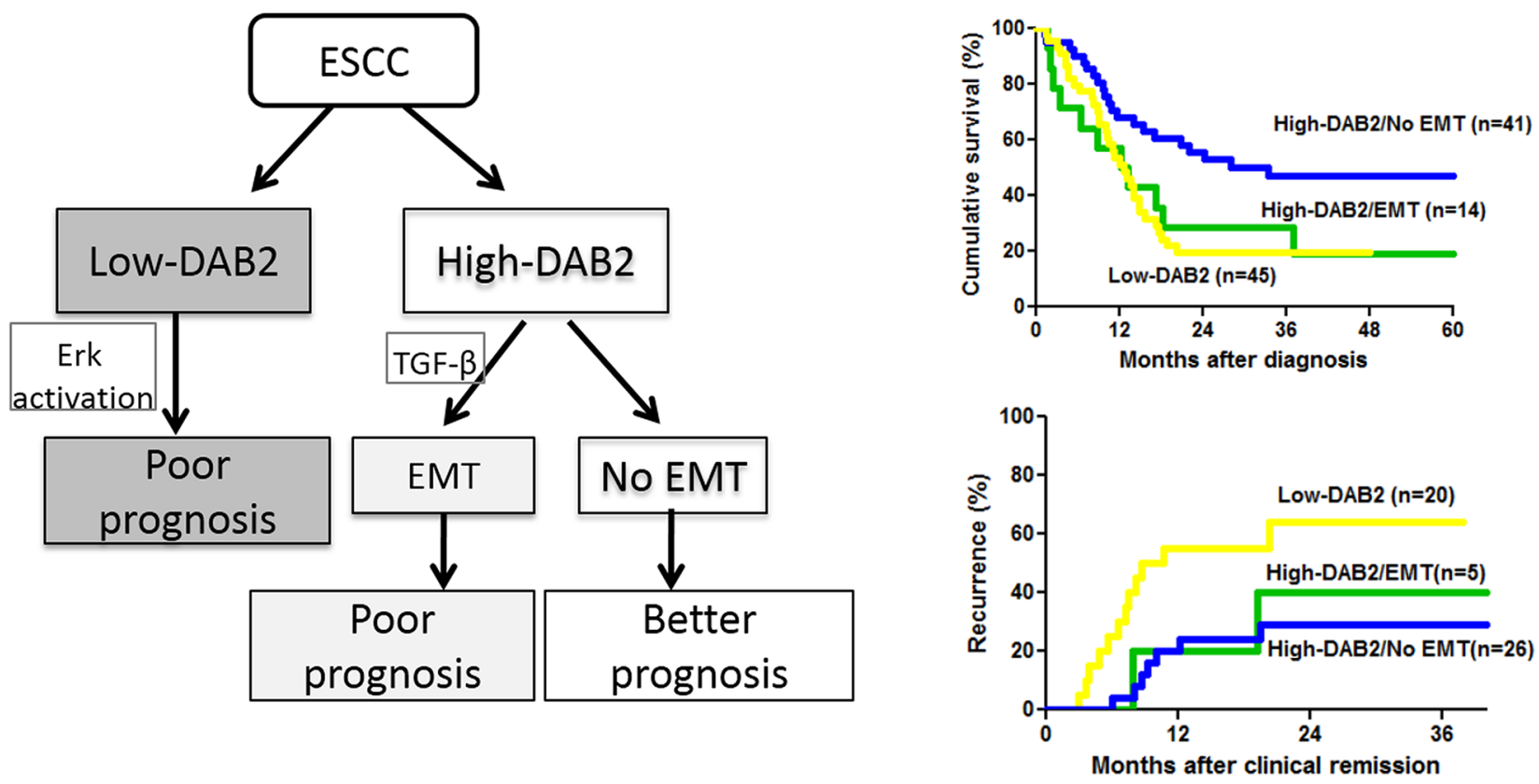

Figure 7: The methylation status of DAB2 promoter and the schematic algorithm demonstrated the three clinical ESCC phenotypes. A. The analysis of DAB2 promoter methylation by MSP in the ESCC cell lines (upper panel) and representative primary tumors (lower panel). U and M refer to the un-methylated and the methylated PCR reactions, respectively. B. The schematic algorithm demonstrated the three clinical ESCC phenotypes, defined by DAB2 and EMT expressions, and their corresponding survival and tumor recurrence rates. 


\section{MATERIALS AND METHODS}

\section{Patients and study design}

This study consecutively enrolled 100 adults with histology-confirmed esophageal squamous cell carcinomas from January 2009 to January 2012. The study protocol conformed to the 1975 Declaration of Helsinki and was approved by the institutional review boards of EDa Hospital (EMRP-20101N) and National Cheng Kung University Medical Center (BR-100-087). Each patient signed their written informed consent to participate in this study, and provide the pre-treatment cancer tissues for the DAB2 expression validation by immunohistochemistry. The clinical staging was verified by computed tomography (CT) scans and endoscopic ultrasound (EUS) to follow the TNM classification system by the American Joint Committee on Cancer [30]. Each study participant was treated after a multi-disciplinary evaluation following the National Comprehensive Cancer Network (NCCN) guidelines. For the patients with stage I or stage II ESCC, curative tumor resection were suggested. For those with stage III cancer, surgery with or without pre-operative chemoradiation therapy were performed. For patients who did not have curative surgery, the initial treatment for the ESCC was definitive concurrent chemoradiation therapy or palliative chemotherapy using platinum-based regimens. We further defined the "clinical complete remission" as the esophageal tumor cannot be detected by endoscopy, histology from endoscopic biopsy, CT, and PET after treatment with curative intent. All of the patients received regular follow-up and the post-treatment survival was evaluated by regular clinic visits, medical records, or telephone contact.

\section{Immunohistochemistry for DAB2 expression, Erk phosphorylation and EMT phenotype}

The esophageal tumor tissue was fixed in $10 \%$ buffered formalin, embedded in paraffin, and serially sectioned at $4 \mu \mathrm{m}$ thickness. To stop endogenous peroxidase activity, the specimen was immersed for 20 mins in 3\% hydrogen peroxide and then pretreated with Dako Cytomation Target Retrieval Solution (Dako, Carpinteria, CA, USA) for antigen retrieval. The tissue section was treated with primary antibody against DAB2 (Catalog sc-13982, Santa Cruz CA, at 1:100 dilution) or against E-cadherin (Cell Signaling, MA, USA, at 1:400 dilution) or against N-cadherin (Abcam, MA, USA, at 1:400 dilution) or phospho-ERK (Cell Signaling, MA, USA, at 1:200 dilution), respectively. Then the sections were incubated overnight in a humidified chamber at $4^{\circ} \mathrm{C}$. The Vectastain Elite ABC Kit (Vector Laboratories Inc., Burlingame, CA, USA) was used for blocking, linkage, and labeling for staining according to the manufacturer's instructions. The Dako Cytomation Liquid DAB Substrate
Chromogen system was used as chromogen. The section was then counterstained with hematoxylin. The pathologist blinded to patients' background scored the staining of DAB2, phospho-ERK, E-cadherin, and N-cadherin expressions.

The expression levels of DAB2 protein in the cytoplasm of tumor cells were scored as the intensity of staining and the percentage of positive-stained cells. The surrounding non-neoplastic stroma served as an internal control for each slide. The staining "intensity" measurements were classified into strong " 2 ", weak " 1 ", or negative " 0 " staining. The staining "percentage" measurements in the tumor tissue were graded as " 3 " if $>60 \%$ tumor cells were immunostaining-positive; " 2 " for $30-60 \%$; " 1 " for $5-30 \%$ and " 0 " if $<5 \%$ were positive. Then the data of DAB2 expression were defined by "intensity x percentage", and further dichotomized into either low-DAB2 ("intensity x percentage" $\leqq 1$ ) or high-DAB2 ("intensity x percentage" $>1$ ) carcinomas, respectively (Figure 1). For those defined as low-DAB2 cancers, a second staining from another tumor section was done.

Semi-quantitative analysis of phospho-ERK staining was assessed as $0,1+, 2+$, and $3+$. Grade 0 is defined as the complete absence or weak phospho-ERK immunostaining in $<5 \%$ of the tumor cells; grade $1+$ is focal positivity in $5-25 \%$ of the tumor cells; grade $2+$ is frequency staining in $25-50 \%$ of the tumor cells; and grade $3+$ is frequency staining in $>50 \%$ of the tumor cells. For E-cadherin, cancer cells were divided into two groups: preserved expression, which indicates cells with the same level of expression as that of normal epithelium, and reduced expression, which indicates cells with weak or absent expression compared with normal epithelium. N-cadherin expression was defined as a positive membranous staining using nerve bundle as internal positive control. The epithelial-tomesenchymal transition (EMT) phenotype was defined as concomitantly reduced expression of E-cadherin to plus a positive expression of $\mathrm{N}$-cadherin.

\section{Cell culture, plasmids and small interference RNA transfection}

The five human esophageal squamous carcinoma cell lines (KYSE-50, KYSE-70, KYSE-150, KYSE-170, KYSE510 ) were purchased from the DSMZ-German Collection of Microorganisms and Cell Cultures (Braunschweig, Germany). All cancer cell lines were cultured in RPMI1640 medium (Gibco, USA), supplemented with 10\% fetal bovine serum. A virus transformed human normal esophageal squamous epithelial cell line (Het-1A) [31] was obtained from the American Type Culture Collection (Manassas, VA, USA) and was maintained in bronchial epithelial cell growth medium (BEGM), supplemented by bronchial epithelial growth media kit (Lonza, Walkersville, MD). All cells were incubated at $37^{\circ} \mathrm{C}$ in $5 \% \mathrm{CO}_{2}$ 
humidified atmosphere. GFP-tagged DAB2 (NM_001343) Human cDNA ORF Clone was purchased from Origene Inc (Cat. No. RG200481). Cell lines were co-transfected with pCMV6-AC-GFP-DAB2 plasmids. Small interference RNA\#1 (siRNA\#1, siGENOME Human DAB2 [1601] siRNA SMART pool) and siRNA\#2 (Dharmacon ${ }^{\mathrm{TM}}$, predesigned siRNA; Sense: 5' C.A.G.C.A.A.A.G.C.A.G.U.U. G.A.G.A.A.U.U.U 3'; Antisense: 5' A.U.U.C.U.C.A.A.C.U .G.C.U.U.U.G.C.U.G.U.U 3') targeted against DAB2 were used for knockdown studies. Cell lines were transfected with siRNA using Lipofectamine 2000, as recommended by the manufacturers (Invitrogen). In parallel, cells untreated and transfected with non-targeting siRNA were used as control.

\section{Western blot analysis}

Cells were washed with ice-cold phosphatebuffered saline (PBS) and lysed in ice-cold radioimmunoprecipitation assay lysis buffer (Sigma, St. Louis, MO, USA). The lysates were then fractionated and separated on $10 \%$ sodium dodecyl sulfate-polyacrylamide gel electrophoresis (SDS-PAGE). The proteins on the gels were transferred to polyvinylidene fluoride (PVDF) membrane (Millipore, Billerica, MA, USA). Then the blots were probed with an antibody specific to DAB2 (Santa Cruz Biotechnology, MA, USA), E-cadherin (Cell Signaling, Danvers, MA, USA), N-cadherin (Abcam, Cambridge, MA, USA), $\beta$-catenin (Abcam), phospho-ERK (Cell Signaling), ERK (Cell Signaling), and appropriate secondary antibodies. The labeled bands were subsequently detected by enhanced chemiluminescence. For each sample, band intensities were normalized to $\beta$-actin.

\section{Wound closure motility assay and transwell migration assay}

Wound closure assay was performed using the IBIDI $^{\mathrm{TM}}$ Culture Inserts system. KYSE cell lines $\left(5 \times 10^{5}\right.$ cells $/ \mathrm{ml} ; 70 \mu \mathrm{l})$ were seeded into the two wells of the culture insert and incubated at $37^{\circ} \mathrm{C}, 5 \% \mathrm{CO}_{2}$ for 16 hours. Then the culture inserts were gently removed to create a cell-free gap of $\sim 500 \mu \mathrm{m}$. Cells migrating into the gap were evaluated under an inverted microscope and the images were collected and analyzed using ImageJ software (National Institutes of Health, Bethesda, MD, USA). Transwell migration assay was performed using CoStar Tranwell chambers ( $8 \mu \mathrm{m}$ pore size, Corning, NY, USA). Cells $\left(1 \times 10^{5} /\right.$ well $)$ were seeded in the upper chambers of the wells in $300 \mu \mathrm{l}$ serum-free medium, and the lower chambers were filled with $700 \mu \mathrm{l}$ medium containing $10 \%$ fetal bovine serum to induce cell migration. The chamber was incubated at $37^{\circ} \mathrm{C}$ for 24 hours. At the end of incubation, the cells in the upper surface of the membrane were removed with a cotton swab. Cells migration to the lower surface of the membrane were fixed with methanol and stained with crystal violet. The images were obtained and the cells were counted with a microscope.

\section{Methylation-specific PCR to define the methylation status of DAB2 promoter}

Genomic DNA was prepared from primary tumor samples and cancer cell lines. The methylation status of $\mathrm{CpG}$-island in DAB2 promoter was analyzed using methylation-specific PCR (MSP) [32]. Genomic DNA $(1 \mu \mathrm{g})$ was subjected to modification with sodium bisulphite, using the EZ DNA methylation kit (Zymo) according to the manufacturer's instruction. Modified DNA was subjected to MSP utilizing the primers and conditions [20]. The methylation-specific primers were 5'-GACCGAAAACTTCGAAACCGCGCGA-3' as the forward primer and 5'-GGGGTTT TTTGCGTCGTTGTAGCGC-3' as the reverse primer, respectively. The unmethylation- specific primers were 5'-ACCAACCAA AAACTTCAAAACCACACAA-3' as the forward primer and $5^{\prime}$-GTGGGGTTTTTTGTG TTGTTGTAGTGT-3' as the reverse primer [20].

\section{Statistical analysis}

The statistics were performed with SPSS software (SPSS for Windows, version 18.0; SPSS Inc., Chicago, IL). The clinical characteristics were compared by $\chi 2$ test or Student's $t$ test between low- and high-DAB2 ESCCs. The study size was at least 100, assuming low and high DAB2 expression distributed in near half. The cumulative survivals of study groups were shown by Kaplan-Meier curves, and their differences were assessed by two-tailed log-rank test. The COX proportional hazard model assess whether DAB2 expression can be independent to predict the survivals and recurrence of ESCC. Correlations between values were evaluated by Spearman's rank correlation. Significance was values of $P<0.05$.

\section{ACKNOWLEDGMENTS}

We are grateful for the supporting from the BioBank, Medical Research Department, E-DA Hospital.

\section{CONFLICTS OF INTEREST}

The authors declare that they have no conflict of interest.

\section{GRANT SUPPORT}

This study was funded in part by research grants from the National Science Council of Taiwan (NSC-1012314-B-650-002-MY2), from the Ministry of Health and Welfare, Taiwan (DOH100-TD-C-111-003), and E-Da Hospital (EDAHP101001). 


\section{REFERENCES}

1. Ferlay J, Shin HR, Bray F, Forman D, Mathers C and Parkin DM. Estimates of worldwide burden of cancer in 2008: GLOBOCAN 2008. Int J Cancer. 2010; 127:2893-2917.

2. Taiwan Cancer Registry (1972-2010). Department of Health, Executive Yuan. Cancer Registry Annual Report. Available at: http://crs.cph.ntu.edu.tw.

3. van Hagen P, Hulshof MC, van Lanschot JJ, Steyerberg EW, van Berge Henegouwen MI, Wijnhoven BP, Richel DJ, Nieuwenhuijzen GA, Hospers GA, Bonenkamp JJ, Cuesta MA, Blaisse RJ, Busch OR, ten Kate FJ, Creemers GJ, Punt CJ, et al. Preoperative chemoradiotherapy for esophageal or junctional cancer. The New England journal of medicine. 2012; 366:2074-2084.

4. Kelsen DP, Ginsberg R, Pajak TF, Sheahan DG, Gunderson L, Mortimer J, Estes N, Haller DG, Ajani J, Kocha W, Minsky BD and Roth JA. Chemotherapy followed by surgery compared with surgery alone for localized esophageal cancer. The New England journal of medicine. 1998; 339:1979-1984.

5. Urba SG, Orringer MB, Turrisi A, Iannettoni M, Forastiere A and Strawderman M. Randomized trial of preoperative chemoradiation versus surgery alone in patients with locoregional esophageal carcinoma. Journal of clinical oncology. 2001; 19:305-313.

6. Fiorica F, Di Bona D, Schepis F, Licata A, Shahied L, Venturi A, Falchi AM, Craxi A and Camma C. Preoperative chemoradiotherapy for oesophageal cancer: a systematic review and meta-analysis. Gut. 2004; 53:925-930.

7. Ando N, Iizuka T, Ide H, Ishida K, Shinoda M, Nishimaki $\mathrm{T}$, Takiyama $\mathrm{W}$, Watanabe $\mathrm{H}$, Isono $\mathrm{K}$, Aoyama N, Makuuchi H, Tanaka O, Yamana H, Ikeuchi S, Kabuto T, Nagai K, et al. Surgery plus chemotherapy compared with surgery alone for localized squamous cell carcinoma of the thoracic esophagus: a Japan Clinical Oncology Group Study--JCOG9204. Journal of clinical oncology. 2003; 21:4592-4596.

8. Osugi H, Takemura M, Higashino M, Takada N, Lee S, Ueno M, Tanaka Y, Fukuhara K, Hashimoto Y, Fujiwara Y and Kinoshita $\mathrm{H}$. Causes of death and pattern of recurrence after esophagectomy and extended lymphadenectomy for squamous cell carcinoma of the thoracic esophagus. Oncology reports. 2003; 10:81-87.

9. Mariette C, Balon JM, Piessen G, Fabre S, Van Seuningen I and Triboulet JP. Pattern of recurrence following complete resection of esophageal carcinoma and factors predictive of recurrent disease. Cancer. 2003; 97:1616-1623.

10. Dresner SM, Wayman J, Shenfine J, Harris A, Hayes N and Griffin SM. Pattern of recurrence following subtotal oesophagectomy with two field lymphadenectomy. The British journal of surgery. 2000; 87:362-373.

11. Thomson IG, Smithers BM, Gotley DC, Martin I, Thomas JM, O'Rourke P and Barbour AP. Thoracoscopic-assisted esophagectomy for esophageal cancer: analysis of patterns and prognostic factors for recurrence. Annals of surgery. 2010; 252:281-291.

12. Lou F, Sima CS, Adusumilli PS, Bains MS, Sarkaria IS, Rusch VW and Rizk NP. Esophageal cancer recurrence patterns and implications for surveillance. Journal of thoracic oncology. 2013; 8:1558-1562.

13. Zhou J and Hsieh JT. The inhibitory role of DOC-2/ DAB2 in growth factor receptor-mediated signal cascade. DOC-2/DAB2-mediated inhibition of ERK phosphorylation via binding to Grb2. J Biol Chem. 2001; 276:27793-27798.

14. He J, Smith ER and Xu XX. Disabled-2 exerts its tumor suppressor activity by uncoupling c-Fos expression and MAP kinase activation. J Biol Chem. 2001; 276:26814-26818.

15. Xu XX, Yi T, Tang B and Lambeth JD. Disabled-2 (Dab2) is an SH3 domain-binding partner of Grb2. Oncogene. 1998; 16:1561-1569.

16. Hocevar BA, Mou F, Rennolds JL, Morris SM, Cooper JA and Howe PH. Regulation of the Wnt signaling pathway by disabled-2 (Dab2). The EMBO journal. 2003; 22:3084-3094.

17. Jiang Y, Prunier C and Howe PH. The inhibitory effects of Disabled-2 (Dab2) on Wnt signaling are mediated through Axin. Oncogene. 2008; 27:1865-1875.

18. Jiang Y, Luo W and Howe PH. Dab2 stabilizes Axin and attenuates Wnt/beta-catenin signaling by preventing protein phosphatase 1 (PP1)-Axin interactions. Oncogene. 2009; 28:2999-3007.

19. Hocevar BA, Smine A, Xu XX and Howe PH. The adaptor molecule Disabled-2 links the transforming growth factor beta receptors to the Smad pathway. The EMBO journal. 2001; 20:2789-2801.

20. Hannigan A, Smith P, Kalna G, Lo Nigro C, Orange C, O'Brien DI, Shah R, Syed N, Spender LC, Herrera B, Thurlow JK, Lattanzio L, Monteverde M, Maurer ME, Buffa FM, Mann J, et al. Epigenetic downregulation of human disabled homolog 2 switches TGF-beta from a tumor suppressor to a tumor promoter. The Journal of clinical investigation. 2010; 120:2842-2857.

21. Martin JC, Herbert BS and Hocevar BA. Disabled-2 downregulation promotes epithelial-to-mesenchymal transition. Br J Cancer. 2010; 103:1716-1723.

22. Prunier C and Howe PH. Disabled-2 (Dab2) is required for transforming growth factor beta-induced epithelial to mesenchymal transition (EMT). J Biol Chem. 2005; 280:17540-17548.

23. Chaudhury A, Hussey GS, Ray PS, Jin G, Fox PL and Howe PH. TGF-beta-mediated phosphorylation of hnRNP E1 induces EMT via transcript-selective translational induction of Dab2 and ILEI. Nat Cell Biol. 2010; 12:286-293.

24. Hussey GS, Link LA, Brown AS, Howley BV, Chaudhury A and Howe PH. Establishment of a TGFbeta-induced 
post-transcriptional EMT gene signature. PloS one. 2012; 7:e52624.

25. Du L, Zhao Z, Ma X, Hsiao TH, Chen Y, Young E, Suraokar M, Wistuba I, Minna JD and Pertsemlidis A. miR-93-directed downregulation of DAB2 defines a novel oncogenic pathway in lung cancer. Oncogene. 2014; 33:4307-4315.

26. Mok SC, Chan WY, Wong KK, Cheung KK, Lau CC, $\mathrm{Ng}$ SW, Baldini A, Colitti CV, Rock CO and Berkowitz RS. DOC-2, a candidate tumor suppressor gene in human epithelial ovarian cancer. Oncogene. 1998; 16:2381-2387.

27. Tseng CP, Ely BD, Li Y, Pong RC and Hsieh JT. Regulation of rat DOC-2 gene during castration-induced rat ventral prostate degeneration and its growth inhibitory function in human prostatic carcinoma cells. Endocrinology. 1998; 139:3542-3553.

28. Bagadi SA, Prasad CP, Srivastava A, Prashad R, Gupta SD and Ralhan R. Frequent loss of Dab2 protein and infrequent promoter hypermethylation in breast cancer. Breast cancer research and treatment. 2007; 104:277-286.

29. Anupam K, Tusharkant C, Gupta SD and Ranju R. Loss of disabled-2 expression is an early event in esophageal squamous tumorigenesis. World J Gastroenterol. 2006; 12:6041-6045.

30. Greene FL PD, Fleming ID, eds. AJCC Cancer Staging Manual. 6th ed. New York, NY: Springer-Verlag; . 2002:pp 31-46 and 91-38.

31. Stoner GD, Kaighn ME, Reddel RR, Resau JH, Bowman D, Naito Z, Matsukura N, You M, Galati AJ and Harris CC. Establishment and characterization of SV40 T-antigen immortalized human esophageal epithelial cells. Cancer Res. 1991; 51:365-371.

32. Herman JG, Graff JR, Myohanen S, Nelkin BD and Baylin SB. Methylation-specific PCR: a novel PCR assay for methylation status of CpG islands. Proc Natl Acad Sci U S A. 1996; 93:9821-9826.

33. Kohno M and Pouyssegur J. Targeting the ERK signaling pathway in cancer therapy. Annals of medicine. 2006; 38:200-211.

34. Klemke RL, Cai S, Giannini AL, Gallagher PJ, de Lanerolle $\mathrm{P}$ and Cheresh DA. Regulation of cell motility by mitogenactivated protein kinase. J Cell Biol. 1997; 137:481-492.

35. Richard DE, Berra E, Gothie E, Roux D and Pouyssegur J. p42/p44 mitogen-activated protein kinases phosphorylate hypoxia-inducible factor 1alpha (HIF-1alpha) and enhance the transcriptional activity of HIF-1. J Biol Chem. 1999; 274:32631-32637.

36. Welch DR, Sakamaki T, Pioquinto R, Leonard TO, Goldberg SF, Hon Q, Erikson RL, Rieber M, Rieber MS,
Hicks DJ, Bonventre JV and Alessandrini A. Transfection of constitutively active mitogen-activated protein/extracellular signal-regulated kinase kinase confers tumorigenic and metastatic potentials to NIH3T3 cells. Cancer Res. 2000; 60:1552-1556.

37. Wang WL, Chang WL, Yeh YC, Lee CT, Chang CY, Lin JT and Sheu BS. Concomitantly elevated serum matrix metalloproteinases 3 and 9 can predict survival of synchronous squamous cell carcinoma of the upper aero-digestive tract. Molecular carcinogenesis. 2013; 52:438-445.

38. Thiery JP. Epithelial-mesenchymal transitions in tumour progression. Nat Rev Cancer. 2002; 2:442-454.

39. Xu J, Lamouille S and Derynck R. TGF-beta-induced epithelial to mesenchymal transition. Cell research. 2009; 19:156-172.

40. Cai Z, Wang Q, Zhou Y, Zheng L, Chiu JF and He QY. Epidermal growth factor-induced epithelial-mesenchymal transition in human esophageal carcinoma cells--a model for the study of metastasis. Cancer letters. 2010; 296:88-95.

41. Lee KW, Kim JH, Han S, Sung CO, Do IG, Ko YH, Um SH and $\mathrm{Kim} \mathrm{SH}$. Twist1 is an independent prognostic factor of esophageal squamous cell carcinoma and associated with its epithelial-mesenchymal transition. Annals of surgical oncology. 2012; 19:326-335.

42. Zhou J, Hernandez G, Tu SW, Scholes J, Chen H, Tseng CP and Hsieh JT. Synergistic induction of DOC-2/DAB2 gene expression in transitional cell carcinoma in the presence of GATA6 and histone deacetylase inhibitor. Cancer Res. 2005; 65:6089-6096.

43. Chao A, Lin CY, Lee YS, Tsai CL, Wei PC, Hsueh $\mathrm{S}$, Wu TI, Tsai CN, Wang CJ, Chao AS, Wang TH and Lai CH. Regulation of ovarian cancer progression by microRNA-187 through targeting Disabled homolog-2. Oncogene. 2012; 31:764-775.

44. Adjei AA, Cohen RB, Franklin W, Morris C, Wilson D, Molina JR, Hanson LJ, Gore L, Chow L, Leong S, Maloney L, Gordon G, Simmons H, Marlow A, Litwiler K, Brown S, et al. Phase I pharmacokinetic and pharmacodynamic study of the oral, small-molecule mitogen-activated protein kinase kinase 1/2 inhibitor AZD6244 (ARRY-142886) in patients with advanced cancers. Journal of clinical oncology. 2008; 26:2139-2146.

45. Gilmartin AG, Bleam MR, Groy A, Moss KG, Minthorn EA, Kulkarni SG, Rominger CM, Erskine S, Fisher KE, Yang J, Zappacosta F, Annan R, Sutton D and Laquerre SG. GSK1120212 (JTP-74057) is an inhibitor of MEK activity and activation with favorable pharmacokinetic properties for sustained in vivo pathway inhibition. Clin Cancer Res. 2011; 17:989-1000. 